\title{
Right trisectionectomy for liver metastasis of granulosa cell tumor: a case report and literature review
}

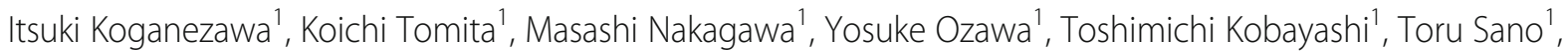
Rina Tsutsui ${ }^{1}$, Naokazu Chiba ${ }^{1}$, Akira Okimura ${ }^{2}$, Munehide Nakatsugawa ${ }^{2}$, Hiroshi Hirano ${ }^{2}$ and Shigeyuki Kawachi ${ }^{1^{*}}$ (D)

\begin{abstract}
Background: Granulosa cell tumor (GCT) is a type of ovarian sex cord-stromal tumor with low-grade malignancy, which can recur long after primary resection. All reports on GCTs in the liver describe cases of metastases, while there are no previous reports of primary GCTs originating from the liver. We report a case of GCT, with recurrence of liver metastasis long after ovariectomy, which was subsequently resected by a right trisectionectomy.

Case presentation: A 76-year-old woman presented with a history of surgical resection of an ovarian tumor performed 30 years previously; no details of the tumor were available. When she was 68 years old, an abdominal ultrasound revealed a small liver mass, which was diagnosed as a hepatic hemangioma with slow growth. Outpatient follow-up was discontinued for 5 years, and the patient was not examined again until the age of 76 years. At this point, the tumor had substantially increased in size, and surgical resection was required owing to suspicion of malignancy. The patient was then referred to our hospital. Contrast-enhanced computed tomography (CT) showed a large tumor, approximately $18 \mathrm{~cm}$ in size, occupying the right lobe and medial section of the liver. After percutaneous transhepatic portal vein embolization, a right trisectionectomy was performed. The histopathological findings of the resected specimen showed that the tumor cells had "coffee bean-like" nuclear grooves, which are characteristic of a GCT. Acidophilic non-structural Call-Exner bodies were also observed. Inhibina, CD99, and CD56 markers of sex cord-stromal tumors were detected on immunohistological examination; all pathology suggested a GCT. We considered the tumor to be a liver metastasis of a previous ovarian GCT that was resected 30 years prior by ovariectomy. There was no recurrence for $>15$ months after the hepatectomy.
\end{abstract}

Conclusions: We report a case of a GCT in the liver, which was identified to be a liver metastasis. Right trisectionectomy was subsequently performed for tumor resection. Clinicians should be aware that ovarian GCTs may recur in the liver, and that GCT recurrence may occur long after ovariectomy of the primary ovarian GCT.

Keywords: Granulosa cell tumor, Liver metastasis, Late recurrence, Right trisectionectomy

\section{Background}

According to the World Health Organization's histological classification of ovarian tumors (2014), a granulosa cell tumor (GCT) is a type of sex cord-stromal

\footnotetext{
* Correspondence: skawachi@tokyo-med.ac.jp

'Department of Digestive and Transplantation Surgery, Tokyo Medical University Hachioji Medical Center, 1163 Tatemachi, Hachiojishi, Tokyo 193-0998, Japan

Full list of author information is available at the end of the article
}

tumor with low-grade malignancy [1]. These sex cordstromal cell tumors comprise of pure sex cord tumors and pure stromal tumors. The GCT is categorized as a pure stromal tumor, accounting for $2-5 \%$ of ovarian tumors and $70 \%$ of sex cord-stromal tumors. The GCT is a relatively rare ovarian tumor classified as either an adult GCT, with an incidence of $95 \%$, or a juvenile GCT, with an incidence of 5\% [2]. A GCT is usually treated by ovariectomy and has a relatively good prognosis; 
however, late recurrence can arise. GCT progression often manifests with pelvic recurrence or peritoneal dissemination; whereas, liver metastasis is rarely noted (5$6 \%$ of cases) [3]. All reports on the occurrence of GCTs in the liver describe cases of metastases [3], but none of these reports have described a GCT originating from the liver. Herein, we report a case of a GCT with a recurrence of liver metastasis long after ovariectomy, which was subsequently treated by right trisectionectomy of the liver.

\section{Case presentation}

A 76-year-old woman presented to our hospital with a history of ovariectomy for an ovarian tumor that was performed 30 years prior. Additional details related to the tumor were unavailable. When she was 68 years old (22 years after the ovariectomy), a local doctor noted a gallbladder polyp and a 3-cm liver mass when performing an abdominal ultrasound. The tumor was considered to be a hepatic hemangioma showing slow growth; however, her outpatient follow-up was discontinued for the next 5 years. A repeat imaging examination revealed that the liver tumor had increased to $17 \mathrm{~cm}$ in size. Consequently, she was referred to our hospital for detailed examination and surgical resection.

Almost all blood tests showed normal results, except for the detection of mild anemia, elevated biliary enzyme levels, and an inflammatory response. The abnormal values were as follows: hemoglobin, $10.3 \mathrm{~g} / \mathrm{dl}$; albumin, $3.0 \mathrm{~g} / \mathrm{dl}$; alkaline phosphatase, $557 \mathrm{U} / \mathrm{l}$; lactate dehydrogenase, $250 \mathrm{U} / \mathrm{l}$; and C-reactive protein, $1.21 \mathrm{mg} / \mathrm{dl}$. The tumor markers, carcinoembryonic antigen, carbohydrate antigen 19-9, $\alpha$-fetoprotein (AFP), protein induced by the absence of vitamin $\mathrm{K}$ or antagonist II, and AFP-L3, were all negative. Further blood tests showed no evidence of viral hepatitis, testing negative for hepatitis $\mathrm{B}$ surface antigens, hepatitis B surface antibodies, and hepatitis $\mathrm{C}$ virus antibodies.

Abdominal ultrasonography performed previously revealed that the tumor was spreading around the right lobe of the liver and appeared to be a combination of two masses. High and low echoes and blood flow signals were detected inside the tumor.

The abdominal contrast-enhanced dynamic computed tomography $(\mathrm{CT})$ image revealed a maximum tumor diameter of $\sim 18 \mathrm{~cm}$ in the right lobe and medial section of the liver (Fig. 1a-c). The tumor had an uneven and prolonged contrast effect during the early and equilibrium phases of imaging, respectively.

Gadolinium ethoxybenzyl diethylenetriaminepentaacetic acid-enhanced magnetic resonance imaging (MRI) showed a tumor with mixed high- and low-signal intensities on T2-weighted imaging (Fig. 2a). The tumor had a mosaic-like internal environment, suggesting bleeding and necrosis. Diffusion-weighted images revealed a highsignal intensity (Fig. 2b). The dynamic 15-min hepatobiliary phase image showed prolongation of the internal contrast effect (Fig. 2c). Positron emission tomography findings did not reveal any significant fluorodeoxyglucose accumulation in the hepatic tumor or other parts of the body. Thus, the tumor was suspected to be a liver hemangiosarcoma. Malignancy was possible since the tumor had grown over time, so we decided to perform a surgical resection, and right trisectionectomy was planned as the tumor occupied the right lobe and medial section of the liver.

The preoperative evaluation of the liver function showed an indocyanine green 15 -min retention rate (ICG-R15) of $13 \%$, and a Child-Pugh score of 5 points. Since our estimation of the remnant liver function using ${ }^{99 \mathrm{~m}}$ Tc-GSA scintigraphy [4] was insufficient, percutaneous transhepatic portal vein embolization (PTPE) was performed to improve the function of the remnant liver. After PTPE, the future liver remnant volume increased from 501 to $636 \mathrm{~mL}$, and the ICG-R15 did not change. According to the ${ }^{99 \mathrm{~m}} \mathrm{Tc}-\mathrm{GSA}$ scintigraphy, the LU15 value-which should be more than 13 to prevent posthepatectomy liver failure-improved from 12.5 to 13.2. Two months after the PTPE, it was decided that surgery would be performed.
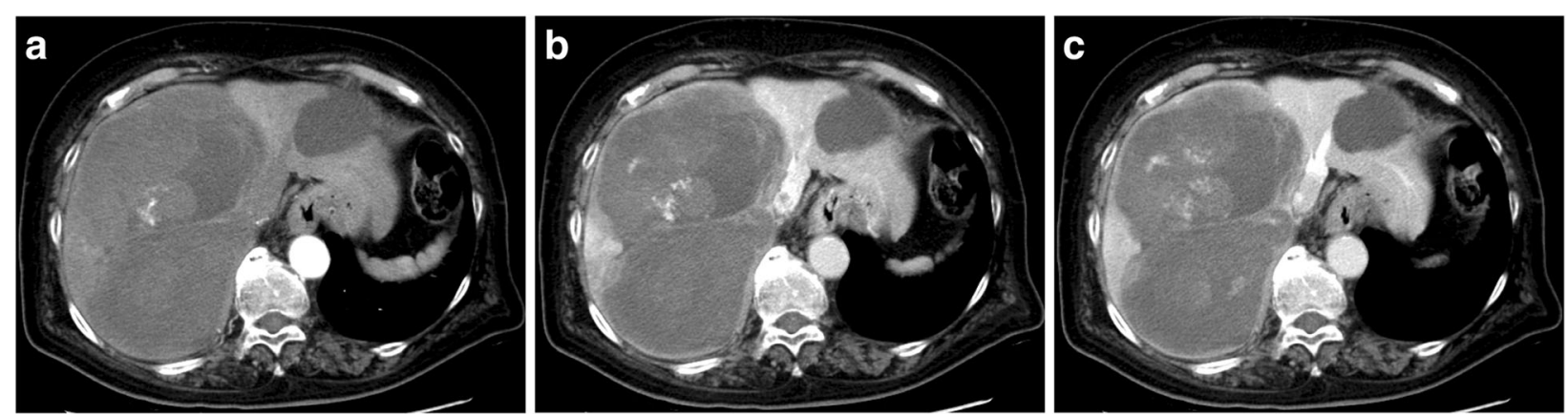

Fig. 1 Computed tomography images. A contrast-enhanced dynamic computed tomography image of a tumor $18 \mathrm{~cm}$ in diameter in the right hepatic lobe. a Arterial phase, $\mathbf{b}$ portal vein phase, and c equilibrium phase 

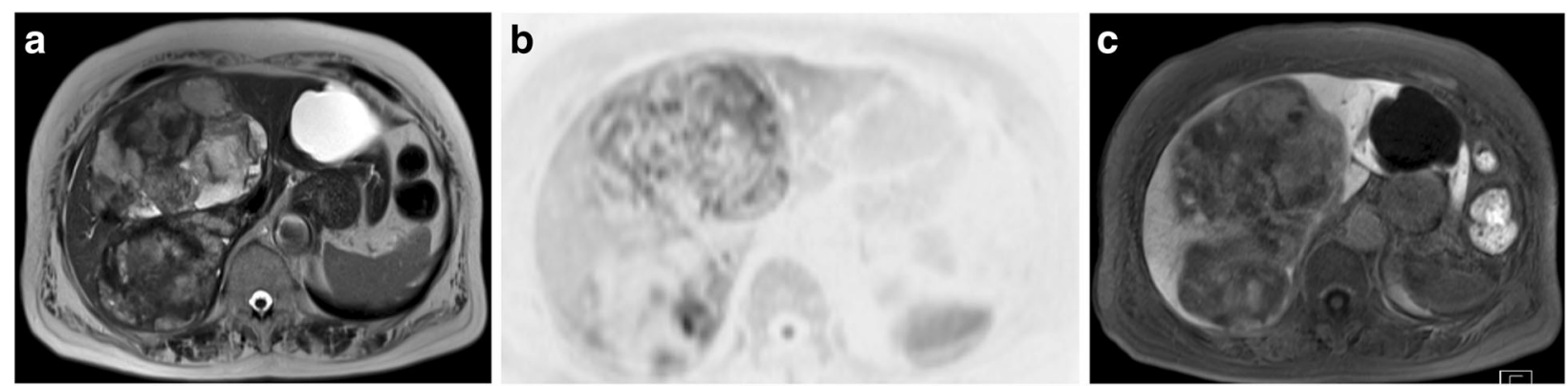

Fig. 2 Magnetic resonance imaging findings. a Magnetic resonance image showing a tumor with mixed high- and low-intensity signals on T2weighted imaging (HASTE). b Diffusion-weighted image showing a high signal intensity of the tumor. c The dynamic 15-mm hepatobiliary phase image of the prolongation of the internal contrast effect

The surgical findings indicated that part of the tumor had invaded the diaphragm and thoracic cavity. Hence, a thoracolaparotomy was performed to remove the tumor by opening the chest through the sixth intercostal space and resecting the tumor that had invaded the diaphragm. We then performed a right hepatic trisectionectomy. The operative time was $306 \mathrm{~min}$, and the estimated blood loss was $1475 \mathrm{ml}$. The size of the resected specimen was $22 \times 17 \times 8 \mathrm{~cm}$ (Fig. 3), and we observed a $10 \times 9 \mathrm{~cm}$ nodule of black-brown and yellowish-white composition with septum formation (Fig. 3). The hematoxylin and eosin (HE)-stained specimens showed tumor cells growing in sheets (diffuse pattern) or cords (trabecular pattern), while rosettes (microfollicular pattern; Fig. 4a) were also visible. The nuclei of the tumor cells were relatively uniform and showed "coffee bean-like" nuclear grooves-characteristic of GCTs (Fig. 4a). Additionally, an acidophilic nonstructural substance (Call-Exner body) was present in the center of the rosette-like structure (Fig. 4a), which is another hallmark characteristic of 30-50\% of GCT cases. Pathological findings were suggestive of a GCT; therefore, we performed additional immunostaining (results are in Table 1). The following markers were identified in the specimen: inhibin- $\alpha$ (Fig. 4b), CD99 (Fig. 4c), and CD56 (Fig. 4d), which were similar to that noted in sex cord-stromal cells $[5,6]$. These findings helped to rule out germ cell tumors, which indicate the presence of other markers that were not detected in our evaluation, including the Sal-like protein, AFP, and $\beta$-human chorionic gonadotropin. Based on these findings, we diagnosed the tumor as a GCT. This tumor may have been a liver metastasis of the ovarian tumor recognized 22 years after the ovariectomy, and the liver metastasis was resected 8 years after its discovery. There was no recurrence for $>15$ months after the hepatectomy.

\section{Conclusions}

We report a case of a GCT with liver metastasis detected 22 years after an ovariectomy which was successfully treated by right trisectionectomy. Preoperatively, a tumor biopsy was not performed, and we could not
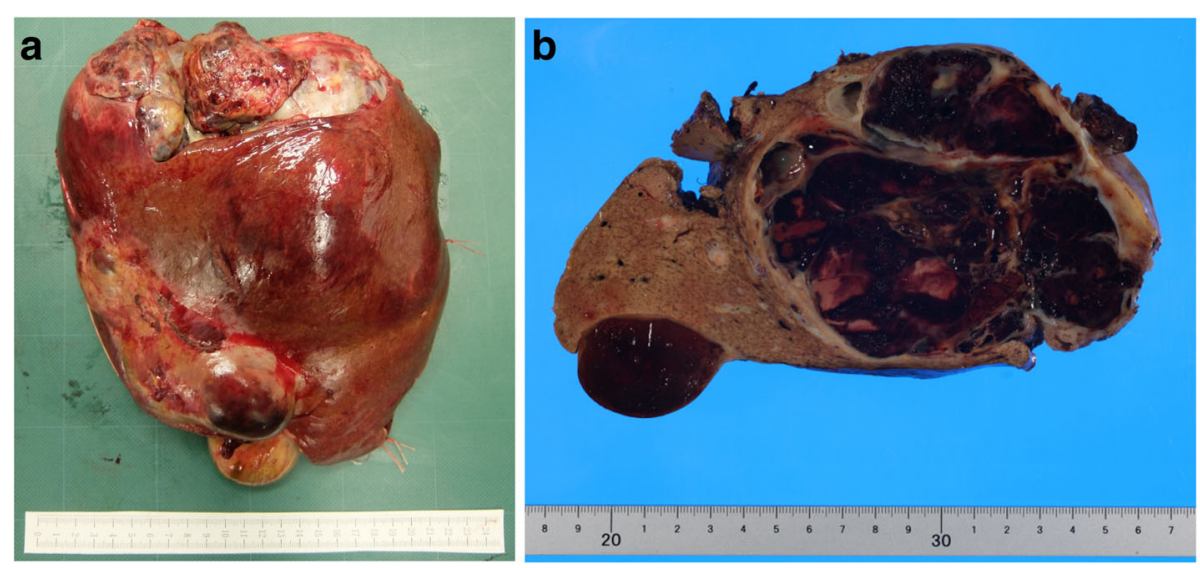

Fig. 3 Surgical specimen. Macroscopically, the tumor has a nodule with a black-brown and yellowish-white composition with septum formation on the cut surface 


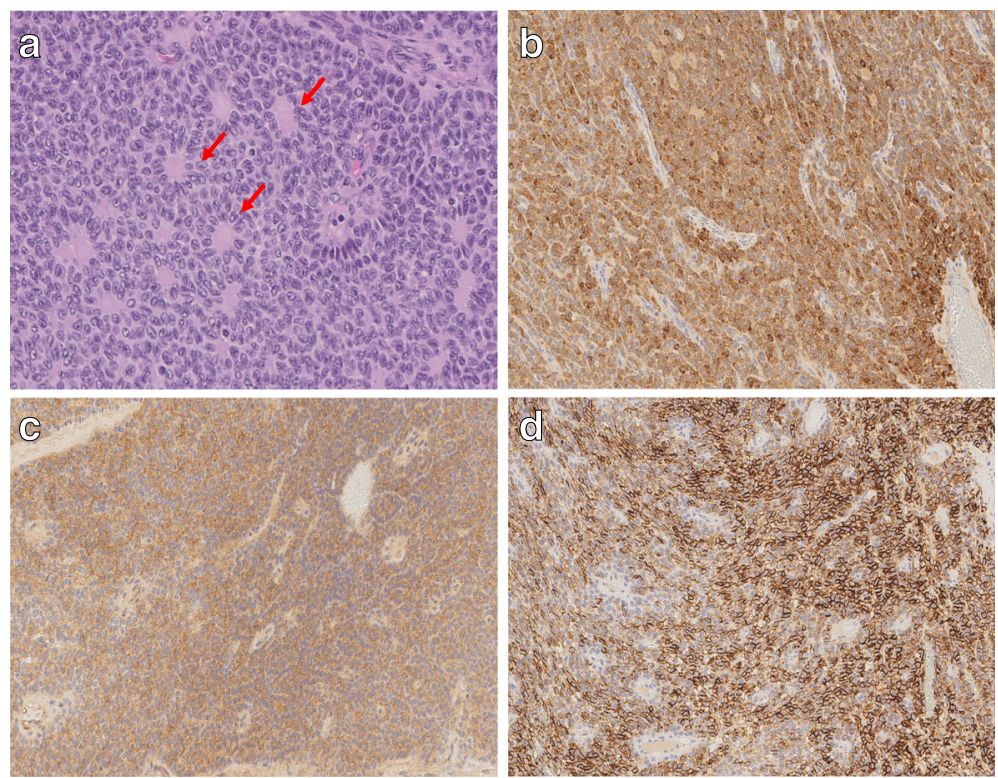

Fig. 4 Immunohistochemical results. a Hematoxylin and eosin-stained image shows an acidophilic non-structural substance (Call-Exner body) in the center of the rosette-like structure (red arrow) and a "coffee bean-like" nuclear groove. Immunostaining is also performed for $\mathbf{b}$ inhibin-a $(x$ 20), $\mathbf{c} \operatorname{CD} 99(\times 20)$, and $\mathbf{d} \operatorname{CD} 56(\times 20)$

achieve an accurate diagnosis. The postoperative pathological findings suggested a GCT. The HE-stained specimens showed tumor cells with "coffee bean-like" nuclear grooves and Call-Exner bodies, which are typical characteristics of GCTs. In our case, a germ cell tumor was considered as a differential diagnosis. However, the immunohistochemical results indicated that markers of sex cord-stromal cells were detected, while markers of germ cell tumors were not. Therefore, the possibility of a germ cell tumor was ruled out. The pathological findings from HE stains and immunohistochemical analysis were consistent with the findings of a GCT. We noted that a GCT originating from the liver had not been previously reported and concluded that this GCT in the liver was a metastatic lesion of an ovarian tumor that was resected 30 years prior.
In total, 17 cases of hepatectomy for GCT liver metastasis, including our case, have been reported since the first description by Garcia et al. in 1996 (Table 2). Most cases had a long time interval between primary diagnosis and hepatectomy, which was similar to our case. In our patient, the GCT presented with liver metastasis 22 years after ovariectomy, which is expected considering that the GCT is known to have a late recurrence. The recurrence rate of GCTs is $32 \%$, and recurrence-free survival for GCTs is 8.4 (6.8-9.9) years [15]. Moreover, tumors often recur after 10 years, with late recurrence of up to 40 years noted in some cases [16]. Therefore, a relatively long-term follow-up is required to monitor the treatment outcomes of GCTs.

Regarding the tumor growth speed, previous reports have described a relatively long interval from the

Table 1 Markers for immunostaining

\begin{tabular}{|c|c|c|}
\hline & Marker & Characteristic \\
\hline \multirow[t]{3}{*}{ Positive } & Inhibin-a & $\begin{array}{l}\text { Inhibin-a is present in most sex cord-stromal cells, and the sensitivity and specificity of inhibin-a for detecting sex cord-stromal } \\
\text { tumors is } 56 \% \text { and } 96 \% \text {, respectively [5]. }\end{array}$ \\
\hline & CD99 & CD99 is detected on the cell surface of Ewing's sarcoma tumors, ependyma, and granulosa cell tumors. \\
\hline & CD56 & $\begin{array}{l}\text { Neuroendocrine tumors are positive for CD56, and CD56 is a marker for granulosa cell tumors. CD56 is useful in distinguishing } \\
\text { between granulosa cell tumors and normal ovarian follicles or endometrioid adenocarcinomas [6]. }\end{array}$ \\
\hline \multirow[t]{3}{*}{ Negative } & SALL4 & SALL4 is a marker for germ cell tumors. \\
\hline & AFP & AFP is a fetal protein and a marker for hepatocellular carcinoma, hepatoblastoma, and germ cell tumors. \\
\hline & $\beta-H C G$ & Villous tumors are positive for HCG. \\
\hline
\end{tabular}


Table 2 Previous reports of patients with GCT liver metastasis who underwent surgical resection

\begin{tabular}{|c|c|c|c|c|c|c|c|}
\hline Authors & $\begin{array}{l}\text { Year of } \\
\text { publication }\end{array}$ & $\begin{array}{l}\text { No. of } \\
\text { cases }\end{array}$ & $\begin{array}{l}\text { Time from primary } \\
\text { diagnosis to hepatectomy } \\
\text { (years) }\end{array}$ & $\begin{array}{l}\text { Time from liver metastasis } \\
\text { to hepatectomy (years) }\end{array}$ & $\begin{array}{l}\text { Surgical } \\
\text { procedure }\end{array}$ & $\begin{array}{l}\text { Combined } \\
\text { resection of other } \\
\text { organs }\end{array}$ & Recurrence \\
\hline $\begin{array}{l}\text { Rodriguez } \\
\text { Garcia Jl, et al. } \\
{[7]}\end{array}$ & 1996 & 1 & 6 & 5 & $\begin{array}{l}\text { Right } \\
\text { hepatectomy }\end{array}$ & No & No \\
\hline Crew et al. [8] & 2005 & 1 & 12 & 10 & Partial & Yes & Yes \\
\hline $\begin{array}{l}\text { Madhuri et al. } \\
\text { [9] }\end{array}$ & 2010 & 3 & $6-17$ & $0-2.7$ & Partial & Yes & No \\
\hline Chua et al. [10] & 2011 & 2 & $6-12$ & $0-14.3$ & $\begin{array}{l}\text { Partial, right } \\
\text { hepatectomy }\end{array}$ & Yes & 1 Yes, 1 no \\
\hline $\begin{array}{l}\text { Andreou et al. } \\
{[11]}\end{array}$ & 2012 & 5 & Unknown & Unknown & Unknown & Unknown & Unknown \\
\hline $\begin{array}{l}\text { Fujita et al. } \\
\text { [12] }\end{array}$ & 2015 & 1 & 25 & Unknown & $\begin{array}{l}\text { Right } \\
\text { hepatectomy }\end{array}$ & Yes & Yes \\
\hline Yu et al. [13] & 2015 & 1 & 27 & Unknown & Bisegmentectomy & No & No \\
\hline $\begin{array}{l}\text { Antony et al. } \\
\text { [14] }\end{array}$ & 2017 & 2 & 5,3 & 4,2 & $\begin{array}{l}\text { Partial, right } \\
\text { hepatectomy }\end{array}$ & Yes & No \\
\hline Present case & 2020 & 1 & 30 & $>8$ & $\begin{array}{l}\text { Right } \\
\text { trisectionectomy }\end{array}$ & No & No \\
\hline
\end{tabular}

GCT granulosa cell tumor

diagnosis of liver metastasis to hepatectomy (Table 2). In our case, the liver metastasis had slow growth before the local doctor first detected it; however, the growth rate later increased. To our knowledge, no previous study has reported the acceleration of tumor growth over time. A GCT is classified as a low-grade malignant tumor that rarely grows rapidly; however, Inada et al. reported a juvenile GCT case that showed a rapid $12 \mathrm{~cm}$ increase in approximately 1 year [17]. In our case, we hypothesized that the nature of the tumor, and the speed of tumor growth, may have changed over time.

There is no standard-of-care or clinical practice guideline recommended for the management of recurrent GCTs; however, various approaches, including surgical resection, chemotherapy, and radiation therapy are used in the clinical setting treating their recurrence GCTs [18-20]. Moreover, previous reports have indicated that surgical resection to eradicate the residual disease can improve a patient's postoperative quality of life and recurrence-free survival $[2,14,21]$. In our case, liver metastasis was assumed to be the only form of GCT recurrence, with no further signs of metastases. Therefore, we performed a right trisectionectomy, which is the most extensive hepatectomy reported thus far (Table 2).

Moreover, this metastatic tumor recurred after a prolong duration of 22 years. It was thought that surgical resection could achieve a disease-free status, and longterm survival was expected. We have followed up with this patient for $>15$ months since the hepatectomy, and no recurrence or metastasis has been detected. Conversely, the possibility of another recurrence cannot be disregarded as GCTs are known for their repeated recurrence. Accordingly, we believe that careful followup is vital for this patient.

We report a case of a GCT in the liver, which was considered to be a liver metastasis and was subsequently resected by performing right trisectionectomy. Clinicians should be aware that ovarian GCTs may recur in the liver, and that this recurrence may occur many years after performing the primary ovarian GCT's ovariectomy.

\section{Abbreviations}

GCT: Granulosa cell tumor; CT: Computed tomography; MRI: Magnetic resonance imaging; AFP: a-Fetoprotein; ICG-R15: Indocyanine green 15-min retention rate; PTPE: Percutaneous transhepatic portal vein embolization; HE: Hematoxylin and eosin

\section{Acknowledgements}

None.

\section{Authors' contributions}

$\mathrm{IK}$ and $\mathrm{KT}$ were involved in the conception and design of this case report. The other authors (MN, TG, YO, TK, TS, RT, NC, AO, HH, and SK) contributed towards the collection, analysis, and interpretation of the data. IK wrote the draft manuscript, and KT critically revised the manuscript. SK gave the final approval for the version to be published and takes overall responsibility for the case report and guarantees the scientific integrity of the manuscript. The authors read and approved the final manuscript.

\section{Authors' information}

IK: Senior resident

Funding

None.

\section{Availability of data and materials}

All data generated or analyzed during this study were included in this published article. 
Ethics approval and consent to participate

Not applicable.

\section{Consent for publication}

The patient provided consent for the publication of her data.

\section{Competing interests}

None.

\section{Author details}

'Department of Digestive and Transplantation Surgery, Tokyo Medical University Hachioji Medical Center, 1163 Tatemachi, Hachiojishi, Tokyo 193-0998, Japan. ${ }^{2}$ Department of Diagnostic Pathology, Tokyo Medical University Hachioji Medical Center, 1163 Tatemachi, Hachiojishi, Tokyo 193-0998, Japan

Received: 7 April 2020 Accepted: 20 May 2020

Published online: 03 June 2020

\section{References}

1. Kurman RJ, Carcangiu ML, Herrington CS, Young RH. Classification of tumors of the ovary. In: WHO Classification of Tumors, editor. World Health Organization, vol. 6. 4th ed. Lyon: IARC; 2014. p. 44-56.

2. Colombo N, Parma G, Zanagnolo V, Insinga A. Management of ovarian stromal cell tumors. J Clin Oncol. 2007:25:2944-51.

3. Simmons RL, Sciarra JJ. Treatment of late recurrent granulosa cell tumors of the ovary. Surg Gynecol Obstet. 1967;124:65-70.

4. Chiba N, Yokozuka K, Ochiai S, Gunji T, Okihara M, Sano T, et al. The diagnostic value of $99 \mathrm{~m}$-Tc GSA scintigraphy for liver function and remnant liver volume in hepatic surgery: a retrospective observational cohort study in 27 patients. Patient Saf Surg. 2018;12:15.

5. Cathro HP, Stoler MH. The utility of calretinin, inhibin, and WT1 immunohistochemical staining in the differential diagnosis of ovarian tumors. Hum Pathol. 2005;36:195-201.

6. Ohishi Y, Kaku T, Oya M, Kobayashi H, Wake N, Tsuneyoshi M. CD56 expression in ovarian granulosa cell tumors, and its diagnostic utility and pitfalls. Gynecol Oncol. 2007;107:30-8.

7. García Jl, González J, González J, Flórez LJ, Rodríguez PF, Rodríguez EM. Hepatic metastases of granulosa cells tumour of the ovary. HPB Surg. 1996; 10:55-7.

8. Crew KD, Cohen MH, Smith DH, Tiersten AD, Feirt NM, Hershman DL. Long natural history of recurrent granulosa cell tumor of the ovary 23 years after initial diagnosis: a case report and review of the literature. Gynecol Oncol. 2005;96:235-40.

9. Madhuri TK, Butler-Manuel S, Karanjia N, Tailor A. Liver resection for metastases arising from recurrent granulosa cell tumour of the ovary--a case series. Eur J Gynaecol Oncol. 2010;31:342-4.

10. Chua TC, lyer NG, Soo KC. Prolonged survival following maximal cytoreductive effort for peritoneal metastases from recurrent granulosa cell tumor of the ovary. J Gynecol Oncol. 2011;22:214-7.

11. Andreou A, Brouquet A, Bharathy KG, Perrier ND, Abdalla EK, Curley SA, et al. Liver resection for liver metastases from nondigestive endocrine cancer: extrahepatic disease burden defines outcome. Surgery. 2012;151:851-9.

12. Fujita F, Eguchi S, Takatsuki M, Kobayashi K, Kanetaka K, Ito M, et al. A recurrent granulosa cell tumor of the ovary 25 years after the initial diagnosis: a case report. Int J Surg Case Rep. 2015;12:7-10.

13. Yu S, Zhou X, Hou B, Tang B, Hu J, He S. Metastasis of the liver with a granulosa cell tumor of the ovary: a case report. Oncol Lett. 2015;9:816-8.

14. Antony M, Pavithran K, Vijayakumar DK, Sudheer OV. Long-term survival following repeat liver resections in metastatic ovarian granulosa cell tumor: case report with review of the literature. South Asian J Cancer. 2017;6:87-8.

15. Chraiet N, Batti R, Ayadi M, Mokrani A, Meddeb K, Yahiaoui Y, et al. Granulosa cell tumor of the ovary: a retrospective study of 31 cases and review of the literature. Int J Surg Oncol. 2018. https://doi.org/10.1155/2018/ 4547892.

16. Kottarathil VD, Antony MA, Nair IR, Pavithran K. Recent advances in granulosa cell tumor ovary: a review. Indian J Surg Oncol. 2013;4:37-47.

17. Inada Y, Nakai G, Yamamoto K, Yamada T, Hirose Y, Terai Y, et al. Rapidly growing juvenile granulosa cell tumor of the ovary arising in adult: a case report and review of the literature. J Ovarian Res. 2018;11:100.
18. Brown J, Brady WE, Schink J, Van Le L, Leitao M, Yamada SD. Efficacy and safety of bevacizumab in recurrent sex cord-stromal ovarian tumors: results of a phase 2 trial of the Gynecologic Oncology Group. Cancer. 2014;120: 344-51.

19. Wagenaar HC, Pecorelli S, Vergote I, Curran D, Wagener DJ, Kobierska A, et al. Phase II study of a combination of cyclophosphamide, adriamycin and cisplatin in advanced fallopian tube carcinoma. An EORTC gynecological cancer group study. European Organization for Research and Treatment of Cancer. Eur J Gynaecol Oncol. 2001;22:187-93.

20. Dubuc-Lissoir J, Berthiaume MJ, Boubez G, Van Nguyen T, Allaire G. Bone metastasis from a granulosa cell tumor of the ovary. Gynecol Oncol. 2001; 83:400-4.

21. Sun HD, Lin H, Jao MS, Wang KL, Liou WS, Hung YC, et al. A long-term follow-up study of 176 cases with adult-type ovarian granulosa cell tumors. Gynecol Oncol. 2012;124:244-9.

\section{Publisher's Note}

Springer Nature remains neutral with regard to jurisdictional claims in published maps and institutional affiliations.

\section{Submit your manuscript to a SpringerOpen ${ }^{\circ}$ journal and benefit from:}

- Convenient online submission

- Rigorous peer review

- Open access: articles freely available online

- High visibility within the field

- Retaining the copyright to your article

Submit your next manuscript at $\boldsymbol{\nabla}$ springeropen.com 